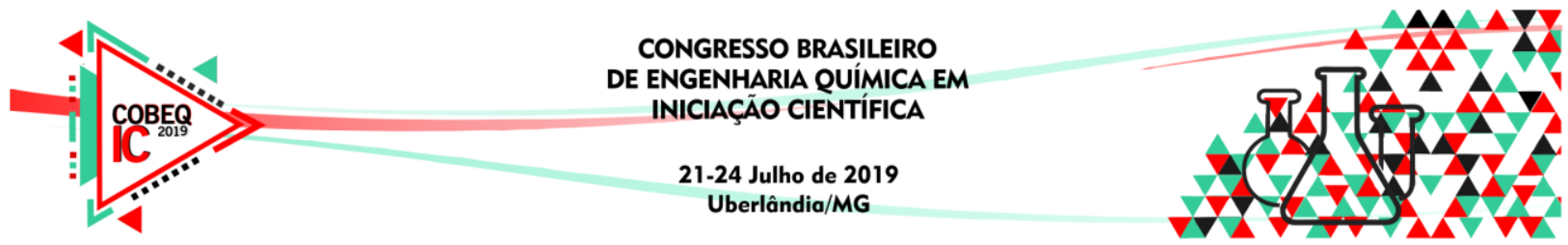

\title{
SÍNTESE E CARACTERIZAÇÃO DA POLIANILINA UTILIZANDO ZINCO METÁLICO COMO ÍON DOPANTE
}

\author{
E. N. CAIXETA ${ }^{1}$, S. L. NOGUEIRA ${ }^{1}$ \\ ${ }^{1}$ Centro Universitário de Patos de Minas, Faculdade de Engenharia Química \\ E-mail para contato: eduardan8@gmail.com
}

\begin{abstract}
RESUMO - O estudo objetivou a síntese do polímero condutor polianilina como sal de esmeraldina (PAni-ES), assim como sua, caracterização e aplicação. Realizaram-se testes de absorção óptica, rendimento, $p \mathrm{H}$ e potencial eletrolítico a fim de perceber as potencialidades que o íon metálico $(\mathrm{Zn})$ poderia fornecer ao polímero. Diante dessa perspectiva, viabilizou-se a produção de uma fita condutora à base de Acetato de polivinila-PVAc e através destes resultados podese comprovar o poder de condutividade dos polímeros assim como quando associado a um íon metálico.
\end{abstract}

\section{INTRODUÇÃO}

O desenvolvimento da tecnologia de síntese e caracterização dos polímeros é um dos assuntos científicos e tecnológicos mais importantes, sendo mais viabilizado a partir da Segunda Guerra Mundial, onde ocorreu uma grande popularização do uso de polímeros pela sociedade (Amaral, T. P. et al 2001). Diante desse cenário houve a necessidade de estudos para questões significativas, como a estrutura, composição e durabilidade desses novos materiais.

O estudo dos polímeros expandiu tanto pela sua importância científica como pelo seu potencial em diferentes setores da tecnologia, podendo ser usado no cotidiano para fabricação de plásticos, eletrodos, materiais de revestimento, anticorrosivos para tintas, dispositivos eletrocrômicos, células solares, músculos artificiais, recobrimento de fibras têxteis, diodos emissores de luz (LED) entre outras (Faez et al.; 2000). No entanto, o desenvolvimento dos processos deste material torna-se importante não somente para pesquisas acadêmicas, mas também abre novas portas na área da tecnologia afetando diretamente o setor industrial.

Um polímero potencialmente condutor deve apresentar cadeias poliméricas conjugadas constituídas por sistemas de elétrons. Tais polímeros passam de isolantes a condutores através de processos de oxidação ou de redução do sistema conjugado. Este processo, também conhecido como dopagem, é reversível e consiste na transferência de carga, que pode ser feita química ou eletroquimicamente (Vicentini, 2006). Dentre os polímeros condutores, a polianilina (PAni),conforme mostra a Figura 1, dispõe de propriedades elétricas, óticas e magnéticas, associadas à estabilidade térmica e facilidade de síntese e dopagem. 


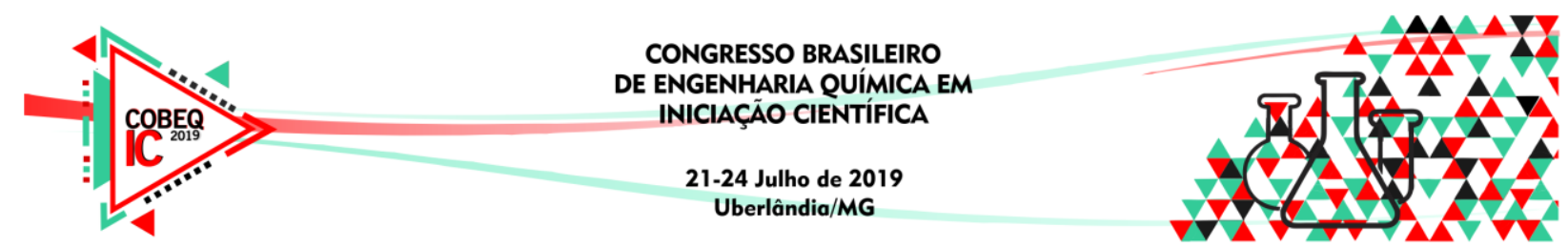

Figura 1 - Polianilina em seu estado natural.

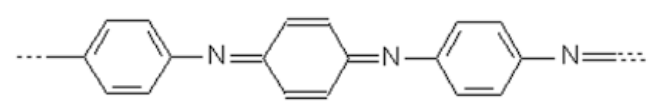

Fonte: FAEZ et al (2000).

Para se produzir um polímero condutor, incialmente o mesmo passa por uma etapa chamada síntese, a qual ocorre de duas formas: química e eletroquímica (Mattoso, 1996). A partir desse processo, a base polimérica passa a funcionar como sal, sendo aderida ao íon metálico de forma mais fácil, pois em sua estrutura, os elétrons conseguem navegar livremente, ou seja, a própria síntese transforma o polímero em um semicondutor como representado na figura 2, onde EB é a base esmeraldina e ES, sal de esmeraldina.

Figura 2 - Esquema básico da síntese da Polianilina.

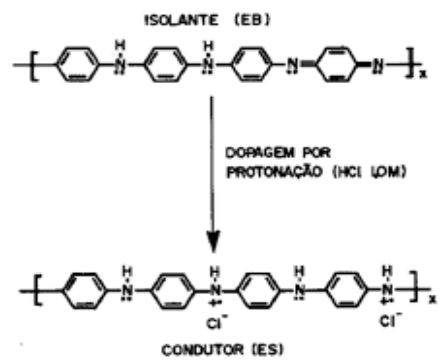

Fonte: FAEZ et al (2000).

A Polianilina (PAni) é o polímero condutor mais analisado por diversos autores, pois é de fácil obtenção, baixo custo e não exige sofisticação na aparelhagem para sua síntese. $\mathrm{O}$ presente trabalho tem como objetivo principal a síntese e dopagem da PAni com o íon metálico Zinco (Zn) e sua aplicação para a formação de uma fita condutora enfatizando aspectos como maleabilidade, condutividade elétrica e resistência.

\section{METODOLOGIA}

Toda a parte experimental foi realizada junto ao Laboratório de Análises Químicas do Centro Universitário de Patos de Minas. Levando em conta uma pré-utilização do material, higienização, calibração de equipamentos, e utilização de todo o material de segurança.

\subsection{SÍNTESE DA POLIANILINA - PANI-ES}

Visando aumentar sua condutividade elétrica, juntamente com a massa molecular, incialmente foi-se realizada síntese da PAni, a qual destilou-se a anilina, cuja temperatura de ebulição é $184,13^{\circ} \mathrm{C}$, posteriormente dissolveu-se $(4 \mathrm{~mL})$ de anilina em $40 \mathrm{~mL}$ de solução de $\mathrm{HCl}-1$ mol. $\mathrm{L}^{-1}$ dentro do balão de fundo redondo, o mesmo foi mantido em um recipiente 


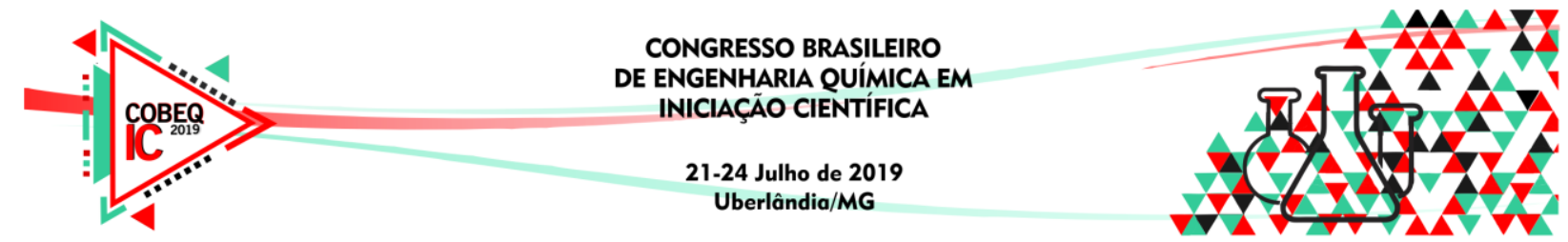

contendo gelo e sal, atingindo aproximadamente $-10^{\circ} \mathrm{C}$, sob constante agitação magnética. Separadamente, dissolve-se $2 \mathrm{~g}$ de persulfato de amônio $\left(\mathrm{NH}_{4}\right)_{2} \mathrm{~S}_{2} \mathrm{O}_{8}$ em $150 \mathrm{~mL}$ de solução de $\mathrm{HCl}-1$ mol. $\mathrm{L}^{-1}$ em um funil de separação. Esta mistura foi adicionada lenta e cuidadosamente ao balão contendo a anilina, sob agitação constante por cerca de $2 \mathrm{~h}$. O meio reacional mudou de coloração para um tom azul esverdeado precipitando ao fundo do frasco, que foi filtrado a vácuo e levado ao dessecador. Após completa secagem, a massa foi pesada em balança analítica para cálculo de rendimento (Fornazier, 2009).

\subsection{DOPAGENS DA POLIANILINA - PANI-ES-ÍON}

Depois de realizada a síntese, obteve-se um polímero fácil de ser manuseado, conhecido como sal de esmeraldina. Diante disso, por meio da exposição direta do polímero a agentes químicos, foi possível transformá-lo em condutor. Nesse processo adicionou-se $0,01 \mathrm{~g}$ da PANI-ES juntamente com $80 \mathrm{~mL}$ de dimetilformamida (DMF) e $50 \mathrm{~mL}$ de solução dopante com o íon metálico (zinco). Em seguida a mistura foi levada para agitação magnética constante durante $24 \mathrm{~h}$. O precipitado formado foi lavado com acetona, filtrado a vácuo e mantido dentro da estufa a uma temperatura constante de $60^{\circ} \mathrm{C}$. Posteriormente, o material seco foi pesado em balança analítica para cálculo de rendimento (Fornazier, 2009).

\section{RESULTADOS E DISCUSSÕES}

Tendo em mente que o íon zinco poderia ser um excelente dopante, encaixando-se no objetivo da aplicação, por apresentar características como flexibilidade, resistência, anticorrosividade, boa reatividade e ainda bom condutor elétrico, efetuaram-se os testes de $p \mathrm{H}$, absorção óptica e potencial eletrônico para a comprovação destas propriedades.

Para a caracterização, realizaram-se os testes de absorção óptica, $p \mathrm{H}$, e condutividade elétrica com o intuito de comprovar os objetivos citados, além de perceber falhas e melhoras, comparando-se as duas dopagens: PAni com o íon metálico e PAni sem o íon metálico o qual foi solubilizado em cerca de $10 \mathrm{~mL}$ de N-metilpirrolidona (NMP) (Fornazier, 2009).

Na caracterização óptica, cada uma das amostras, PAni-ES, PAni-ES-íon, foram levadas separadas ao leitor de absorção óptica de marca Thermo Spectronic, realizando a varredura no comprimento de onda de 200-800 nm. Dos resultados extraídos construiu-se um gráfico para interpretação da varredura comparada com a literatura.

Os espectros, apresentados no gráfico 1, apresentam uma banda posicionada no comprimento de onda $265 \mathrm{~nm}$ e logo depois em $280 \mathrm{~nm}$ claramente formam um pico. De acordo com Fornazier et al. (2009) esta banda é atribuída à transição $\pi-\pi$ e transferência de carga entre anéis benzenóides e quinóides que ocorreu até o comprimento de onda $315 \mathrm{~nm}$.

Estas bandas características são mostradas no gráfico 1. É possível observar que a curva (azul) do polímero não dopado não alcançou harmonia no gráfico, já a curva (verde) do íon dopado obteve melhor estabilização e a diluição auxiliou com que a amostra tornasse mais legível. 


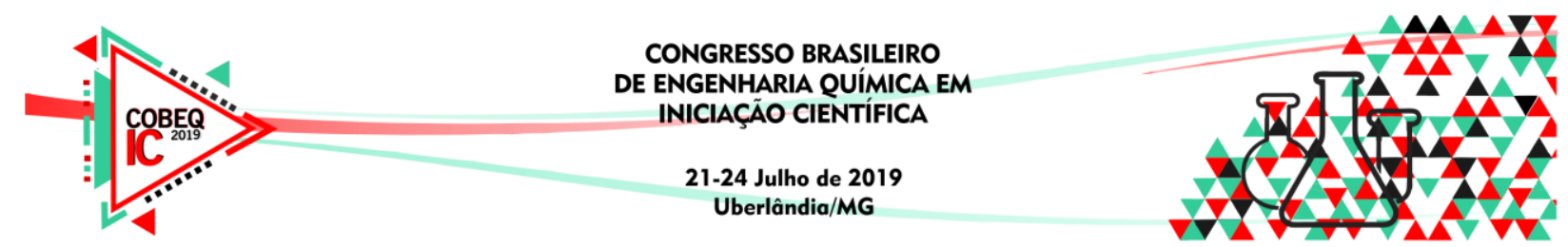

Gráfico 1 - Absorção óptica da PAni dopada e não dopada diluída em DMF.

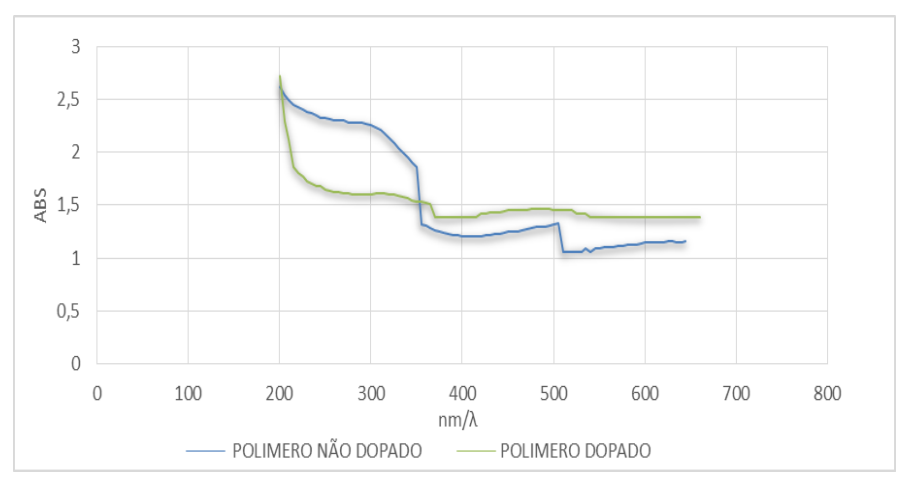

Fonte: Autores da pesquisa (2018).

O Gráfico 2 de Yonis Fornazier Filho (2009) mostra a síntese em seu estudo da PAni em solução de NMP. Em comparação com o gráfico obtido a partir deste estudo, analisando a linha verde da PAni-ES pode-se aferir que assemelha-se com a linha do polímero dopado do gráfico 1, evidenciando a validade e qualidade da síntese o que define que o alcanço do objetivo deste trabalho.

Após a diluição a varredura tornou-se mais legível equiparando-se a banda correspondente a PAni-ES. As alterações devem-se ao fato de que depois de dopada com o íon Zinco, a polianilina possa perder suas características de elemento puro.

Gráfico 2 - Espectros UV-VIS das amostras de PAni em solução de NMP.

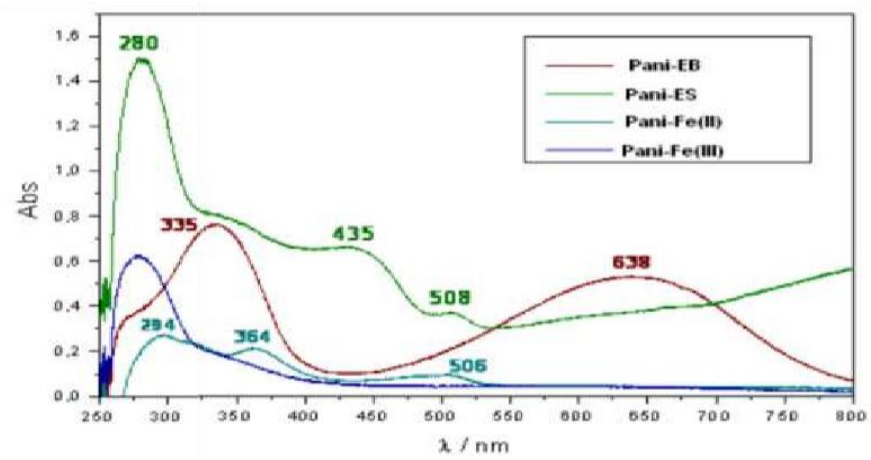

Fonte: Yonis Fornazier Filho, 2009.

Após as medidas de absorção óptica, para a construção da fita eletrônica foi utilizado (q.s.p) Acetato de Polivinil - PVAc (cola branca) como base vertendo o polímero dopado seco. Separadamente outro ensaio com o mesmo polímero, no entanto, solubilizado em DMF (dimetilformamida) foi realizado a fim de comparação, formando uma base circular plana auto suportada de aproximadamente $7,0 \mathrm{~cm}$ de diâmetro para a medida de condutividade. 


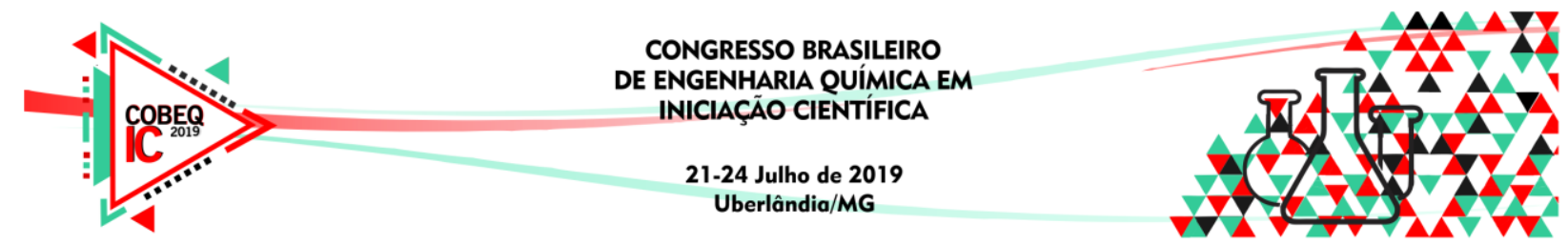

Depois da preparação da fita condutora, a mesma foi levada à um multímetro (com 6 dígitos para melhor exatidão) em que foi aferido o valor da condutividade com unidade em $\mu \Omega\left(10^{-6} \Omega\right)$. Nesta mesma fita foi necessário a medição em seis pontos diferentes que relaciona resistência com resistividade (condutividade) de acordo com as equações 1 e 2 .

$$
\begin{aligned}
\rho & =\frac{R}{d} \\
\sigma & =\frac{1}{\rho}
\end{aligned}
$$

Os resultados da tabela 1 sobre a condutividade elétrica da PAni-ES antes e após a diluição, em comparação com a literatura os valores obtidos desta análise estão dentro do padrão que vai de $10 \mathrm{a} 10^{3} \mathrm{~S} . \mathrm{m}^{-1}$. Em relação ao íon utilizado não foi encontrado na literatura, mas o comparando com a PAni-ES também obteve resultado semelhante, o que comprova sua condutividade.

Tabela 1 - Condutividade elétrica da polianilina ES em solução.

\begin{tabular}{|c|c|c|c|c|}
\hline Polímero & $\begin{array}{c}\text { Condutividade } \\
\text { elétrica antes da } \\
\text { diluição } \\
\left(\mu \mathrm{S} . \mathrm{m}^{-1}\right)\end{array}$ & $\begin{array}{c}\text { Condutividade } \\
\text { elétrica após } \\
\text { diluição }\left(\mu \mathrm{S} . \mathrm{m}^{-1}\right)\end{array}$ & $\begin{array}{c}\text { Condutividade } \\
\text { elétrica }\left({\left.\mathrm{S} . \mathrm{m}^{-1}\right)}^{\mathrm{PUC}}\right)\end{array}$ & $\begin{array}{c}\text { Faez } \text { et. } \text { al } \\
(2010)\end{array}$ \\
\hline PAni-ES & 147,90 & 88,70 & $30-200$ & $10-10^{3}$ \\
\hline PAni-ES-íon & 25,20 & 122,30 & $10^{2}-10^{5}$ & - \\
\hline
\end{tabular}

Fonte: Autores da pesquisa (2018).

Já na tabela 2 a condutividade foi testada em base de acetato de polivinil o material usado para a aplicação, do mesmo modo, os valores estão dentro da literatura. Em uma comparação com a tabela 1, a condutividade do íon aplicado no material aumentou consideravelmente, comprovando que o íon aplicado na base de acetato de polinivil é de 3 a 4 vezes mais propicio a conduz eletricidade do que o íon dopado em solução (puro).

\begin{tabular}{|c|c|c|c|c|}
\hline Polímero & $\begin{array}{l}\text { Condutividade } \\
\text { elétrica antes da } \\
\text { diluiçãão } \\
\left(\mathrm{S} . \mathrm{m}^{-1}\right)\end{array}$ & $\begin{array}{l}\text { Condutividade } \\
\text { elétrica pós } \\
\text { diluição }\left(\mathrm{S} \cdot \mathrm{m}^{-1}\right)\end{array}$ & $\begin{array}{l}\text { Condutividade } \\
\text { elétrica }\left(\text { S.m }^{-1}\right) \\
\text { PUC-Rio }(2010)\end{array}$ & $\begin{array}{l}\text { Faez et. al } \\
\quad(2000)\end{array}$ \\
\hline PAni-ES & $8,5315 \times 10^{2}$ & $89,7098 \times 10^{3}$ & $30-200$ & $10-10^{3}$ \\
\hline PAni-ES-íon & $22,23735 \times 10^{4}$ & $87,9169 \times 10^{4}$ & $10^{2}-10^{5}$ & - \\
\hline
\end{tabular}

Tabela 2 - Condutividade elétrica da polianilina ES em base de Acetato de Polivinilo - PVAc.

Fonte: Autores da pesquisa (2018).

Para aferição do $p \mathrm{H}$ foi realizada a limpeza e calibração do phmetro de marca mpA 2010. Logo após, em um recipiente adequado previamente higienizado, imergiu-se o eletrodo diretamente no polímero para aferição (Fornazier, 2009). 


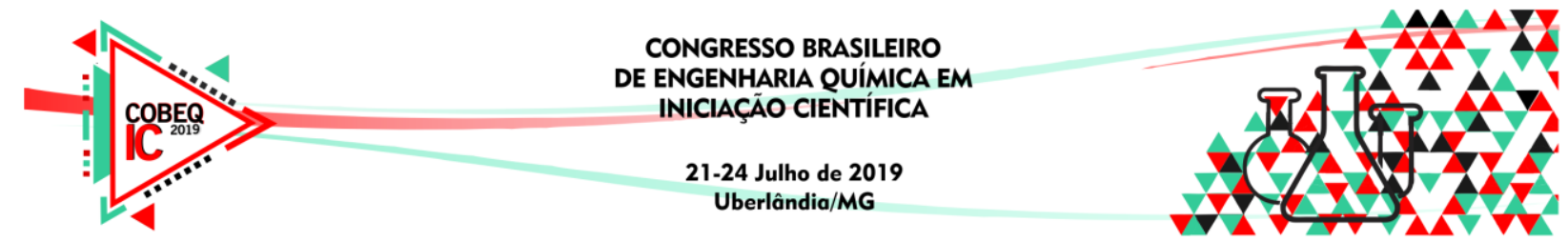

A seguinte tabela relata valores de $p \mathrm{H}$ para a PAni-ES não dopada e dopada, que se assemelham com os valores encontrados na literatura.

Tabela 3 - $p \mathrm{H}$ da solução de PAni-Es em DMF.

\begin{tabular}{|c|c|c|}
\hline Polímero & $p \mathrm{H}$ & Mattoso, (1996) \\
\hline PAni-ES & 2,25 & 3,15 \\
\hline PAni-ES-íon & 5,10 & 4,52 (Íon Fe II) \\
\hline
\end{tabular}

Fonte: Autores da pesquisa (2018).

\section{CONCLUSÃO}

O presente trabalho estudou os polímeros condutores assim como suas possíveis utilizações em diversos setores de aplicação. Foram estudadas também suas caracterizações, síntese e inserção de íons metálicos em sua cadeia polimérica, com o objetivo de proporcionar maior resistência ao polímero assim como seu potencial eletrolítico. Dessa forma, foi realizada aplicação e criação de uma fita eletrônica a fim de mostrar como os polímeros dopados podem conduzir eletricidade facilmente.

Portanto de acordo com os resultados apresentados, comparando-os com os presentes na literatura, observaram-se valores próximos aos testes realizados, além de declarar o íon zinco tornou um excelente condutor ligado a polímeros.

Além de mostrar características como condutividade elétrica, resistência, maleabilidade e elasticidade. Diante deste aspecto pode-se concluir o poder de condutividade dos polímeros assim como este mesmo elevado quando conjugado a um íon metálico.

\section{REFERÊNCIAS}

AMARAL, T. P. et al - Propriedades de compósitos condutivos de polianilina e resina epoxílica. Polímeros: Ciência e Tecnologia, vol. 11, n3, p. 149-157, 2001. NÃO ESTA NO TEXTO

FAEZ, R., REIS, C., SCANDIUCCI DE FREITAS. P., KOSIMA, O.K., RUGGERI, G., e DE PAOLI, M.A., Polímeros Condutores, Química Nova na Escola, n.11, Maio de 2000, p. 1318.

FORNAZIER, Y. F., Síntese, dopagem e caracterização da polianilina com sais de FeII e FeIII, Universidade Federal do Espírito Santo Centro de Ciências Exatas Programa de PósGraduação em Química. Vitória, 2009.

VICENTINI, Denice Schulz. "Preparação e Caracterização de Blendas de Polianilina/Poliuretano Termoplástico Condutoras de Eletricidade.” Universidade Federal de Santa Catarina Programa de Pós-Graduação em Ciências e Engenharia de Materiais. Florianópolis, 2006.

MATTOSO, L.H.C., Polianilinas: Síntese, Estruturas e Propriedades, Química Nova, v.19, n.4, p.388-399, 1996. 